University of Nebraska - Lincoln

DigitalCommons@University of Nebraska - Lincoln

January 2007

\title{
Structure and magnetic properties of $\mathrm{Mn}$-doped $\mathrm{ZnO}$ thin films
}

\author{
Jun Zhang \\ University of Nebraska - Lincoln \\ Xingzhong Li \\ University of Nebraska - Lincoln, xli2@unl.edu \\ J. Shi \\ University of Nebraska - Lincoln \\ Yongfeng Lu \\ University of Nebraska - Lincoln, ylu2@unl.edu \\ David J. Sellmyer \\ University of Nebraska-Lincoln, dsellmyer@unl.edu
}

Follow this and additional works at: https://digitalcommons.unl.edu/physicssellmyer

Part of the Physics Commons

Zhang, Jun; Li, Xingzhong; Shi, J.; Lu, Yongfeng; and Sellmyer, David J., "Structure and magnetic properties of Mn-doped ZnO thin films" (2007). David Sellmyer Publications. 205.

https://digitalcommons.unl.edu/physicssellmyer/205

This Article is brought to you for free and open access by the Research Papers in Physics and Astronomy at DigitalCommons@University of Nebraska - Lincoln. It has been accepted for inclusion in David Sellmyer Publications by an authorized administrator of DigitalCommons@University of Nebraska - Lincoln. 


\title{
Structure and magnetic properties of Mn-doped $\mathrm{ZnO}$ thin films
}

\author{
Jun Zhang ${ }^{1,2}$, X. Z. Li ${ }^{2}$, J Shi ${ }^{2,3}$, Y. F. Lu ${ }^{2,3}$, and \\ D. J. Sellmyer ${ }^{1,2}$ \\ ${ }^{1}$ Department of Physics and Astronomy, University of Nebraska, Lincoln, NE \\ 68588, USA \\ ${ }^{2}$ Nebraska Center for Materials and Nanoscience, University of Nebraska, Lin- \\ coln, NE 68588, USA \\ ${ }^{3}$ Department of Electrical Engineering, University of Nebraska, Lincoln, $N E$ \\ 68588, USA
}

\begin{abstract}
We report the structure and magnetic properties of $\mathrm{Zn}_{1-x} \mathrm{Mn}_{x} \mathrm{O}$ thin films grown on $\mathrm{Si}(001)$ substrates by pulsed laser deposition. Structure and phase evolution with $\mathrm{Mn}$ doping has been studied using $\mathrm{x}$-ray diffraction, electron diffraction, and high-resolution electron microscopy. The undoped and 1\% Mn-doped $\mathrm{ZnO}$ films are completely (001) oriented, and further Mn doping deteriorates the (001) orientation. For Mn concentrations below 3\%, only the hexagonal $\mathrm{ZnO}$ phase exists in the films without secondary phases. As the Mn concentration reaches $5 \%$, secondary phase $\mathrm{Mn}_{2} \mathrm{O}_{3}$ was found aggregating at grain boundaries. All the Mn-doped films show ferromagnetic properties at room temperature, and the magnetic moment decreases as the Mn concentration increases. Our results suggest that the ferromagnetism observed in $\mathrm{Zn}_{1-x} \mathrm{Mn}_{x} \mathrm{O}$ thin films is intrinsic rather than associated with secondary phases.
\end{abstract}

The prediction of high-temperature ferromagnetism (FM) in ZnO-based diluted magnetic semiconductors has stimulated considerable research [1-3]. The $\mathrm{Mn}-\mathrm{Zn}-\mathrm{O}$ system has attracted much attention because of the controversial magnetic properties reported, but their basic origins remain unclear. Both the existence and absence of FM have been reported in Mn-doped $\mathrm{ZnO}$ thin films. Spin-glass behavior [4], paramagnetism [5], FM with a $T_{\mathrm{C}}$ of $45 \mathrm{~K}$ [6], and room-temperature FM [7] have been observed. This suggests a strong dependence of magnetic properties on the sample-preparation conditions [8]. The recently observed FM in $\mathrm{Mn}-\mathrm{Zn}-\mathrm{O}$ bulk materials synthesized at a low temperature of $500{ }^{\circ} \mathrm{C}$ has been argued to arise from the presence of modified manganese oxides, instead of intrinsically from $\mathrm{ZnO}$ with $\mathrm{Mn}$ substituting for $\mathrm{Zn}[9,10]$. Kundaliya et al [9] proposed that the FM originates from an oxygen-vacancy-stabilized metastable phase, probably in the form of $\mathrm{Mn}_{2-x} \mathrm{Zn}_{x} \mathrm{O}_{3-\delta}$. Recently, Garcia et al [10] associated the FM with a coexistence of $\mathrm{Mn}^{3+}$ and $\mathrm{Mn}^{4+}$ in manganese oxides via a double-exchange mechanism. In both of these cases, manganese oxides with diffused $\mathrm{Zn}$ are considered to be responsible for the FM. 
The solubility of $\mathrm{Mn}$ in the low-temperature synthesized bulk $\mathrm{ZnO}$ is very low, and manganese oxides exist with as little as only $1 \%$ Mn doping [8].

It is believed that $\mathrm{Mn}$ has higher solubility in $\mathrm{ZnO}$ thin films grown by pulsed laser deposition (PLD), which is a non-equilibrium process [11]. Fabrication of Mn-doped $\mathrm{ZnO}$ thin films without manganese oxides can facilitate the investigation and understanding of the magnetic properties of this material. In this paper, we report a systematic study of the structure and magnetic properties of $\mathrm{Mn}$-doped $\mathrm{ZnO}$ thin films grown by PLD, with special attention given to examining the possible existence of manganese oxides or other impurity phases. We found that for Mn concentrations below 3\%, no manganese oxides exist in the Mn-doped $\mathrm{ZnO}$ thin films, while as $\mathrm{Mn}$ concentration reaches $5 \%, \mathrm{Mn}_{2} \mathrm{O}_{3}$ was found aggregating at grain boundaries. But FM is observed at low Mn concentrations, without the presence of any impurity phase.

Mn-doped $\mathrm{ZnO}\left(\mathrm{Zn}_{1-x} \mathrm{Mn}_{x} \mathrm{O}, x=0-0.05\right)$ thin films were grown on $\mathrm{Si}(001)$ substrates by PLD. $\mathrm{Zn}_{1-x} \mathrm{Mn}_{x} \mathrm{O}$ ceramic targets were prepared by standard solid-state reaction. The base pressure of the PLD chamber was $2 \times 10^{-7}$ Torr. During film growth the oxygen pressure in the chamber was kept at $5 \times 10^{-4}$ Torr and the substrate temperature was $500{ }^{\circ} \mathrm{C}$. The film thickness varies from 200 to $600 \mathrm{~nm}$. Energy dispersive $\mathrm{x}$-ray spectroscopy (EDS) was used to measure the Mn concentrations. The film structure was characterized using x-ray diffraction, electron diffraction, and high-resolution electron microscopy. Magnetic measurements were made in a superconducting quantum interference device (SQUID) magnetometer (Quantum Design, MPMS-XL).

The film structure was first studied by x-ray diffraction using a Rigaku diffractometer (D/Max-B, $\mathrm{Cu} \mathrm{K} \alpha, \lambda=0.154 \mathrm{~nm})$. Figure 1 shows the $\mathrm{x}$-ray diffraction patterns of $\mathrm{Zn}_{1-x} \mathrm{Mn}_{x} \mathrm{O}$ thin films with $\mathrm{Mn}$ concentration varying from 0 to $5 \%$. The undoped and $1 \%$ Mn-doped $\mathrm{ZnO}$ films show good (001) orientation, with only (002) and (004) diffraction peaks from the hexagonal $\mathrm{ZnO}$ phase. However, as $\mathrm{Mn}$ concentration increases up to 3\%, the (001) orientation deteriorates. Besides the peaks from the Si substrate, there are strong (002) and (004) peaks and very weak (100) and (103) peaks, all of which belong to the $\mathrm{ZnO}$ hexagonal phase, indicating preferred (001) orientation and a small amount of randomly distributed grains. As Mn concentration increases, the $\mathrm{ZnO}(002)$ and (004) peaks shift slightly to lower angles. As shown in figure 2, the lattice parameter $c$ derived from the (002) diffraction lines increases as Mn content increases, suggesting that Mn substitutes for $\mathrm{Zn}$ in $\mathrm{ZnO}$ lattice, at least in the (001) oriented grains. No manganese oxides have been detected according to $\mathrm{x}$-ray diffraction results.

The evolution of the structure properties of the $\mathrm{Zn}_{1-x} \mathrm{Mn}_{x} \mathrm{O}$ films with increased $\mathrm{Mn}$ concentration was further studied using transmission electron microscopy (Jeol JEM2010, $200 \mathrm{kV}$ ). Shown in figure 3 are the plane-view high-resolution electron microscopy (HREM) images of $\mathrm{Zn}_{1-x} \mathrm{Mn}_{x} \mathrm{O}$ thin films with an incident beam parallel to the normal of the film. The HREM image of the film with $x=0.01$ (figure 3(a)) shows grains with very clean and sharp grain boundaries, and no secondary phase aggregations are found at grain boundaries. Adjacent grains directly meet each other without separations. The lattice image is clearly visible throughout the whole grains. Within the grains, although there are areas with significant contrast, the array of the spots is continuous across the dark and light areas, suggesting that these areas have the same $\mathrm{ZnO}$ hexagonal phase and excluding the possibility that the contrast is due to the existence of different phases. The contrast probably comes from crystal imperfections, such as dislocations or stacking faults. In the centre of the dark areas there are interruptions in the array of spots, indicating the existence of defects.

As the Mn concentration reaches 0.05 , however, the HREM image shown in figure 3(b) reveals different features. Grains are separated by aggregations clearly observed at 


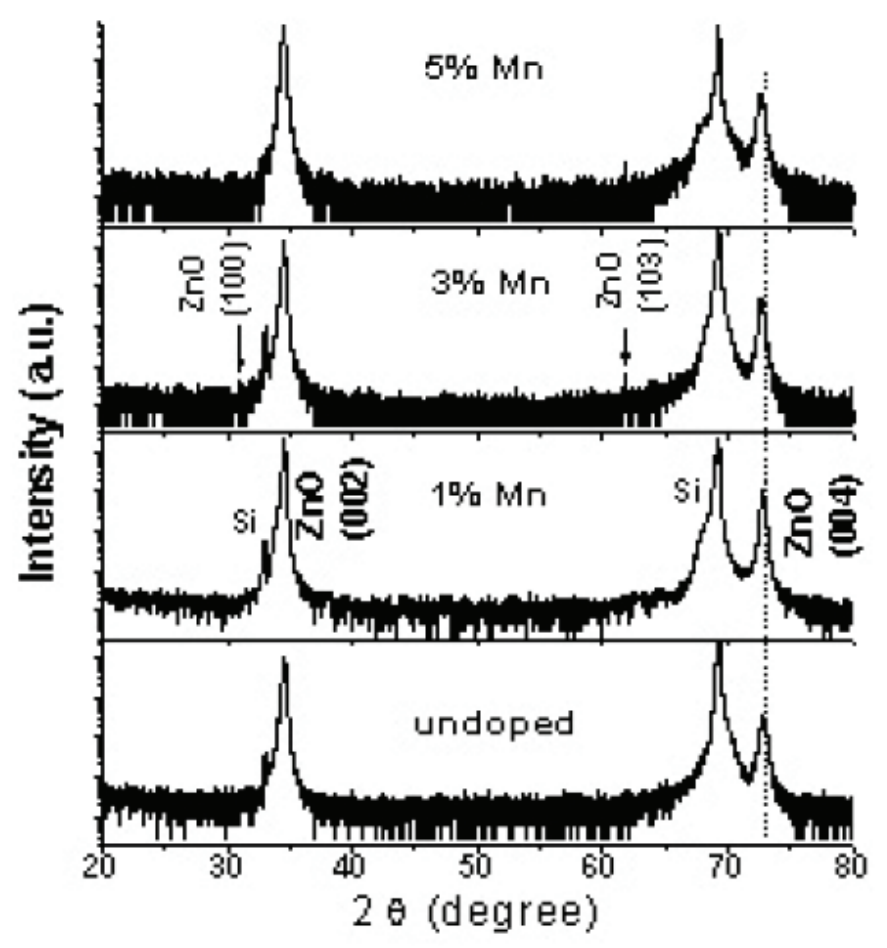

Figure 1. X-ray diffraction pattern of $\mathrm{Zn}_{1-x} \mathrm{Mn}_{x} \mathrm{O}$ thin films $(x=0,0.01,0.03$, and 0.05). The intensity axis is plotted on a log scale. The dashed line is plotted to show the shift of the $\mathrm{ZnO}(004)$ peak.

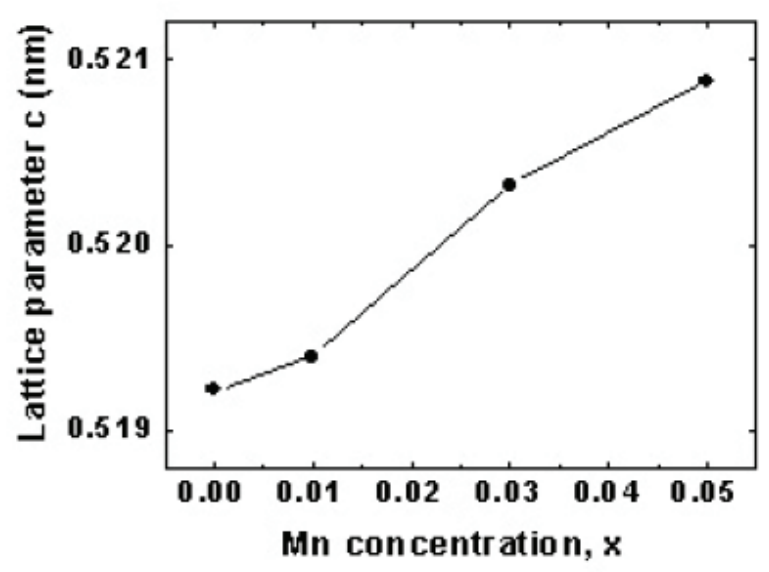

Figure 2. Mn concentration dependence of the lattice parameter $c$ of $\mathrm{Zn}_{1-x} \mathrm{Mn}_{x} \mathrm{O}$ thin films derived from the (002) spacing.

grain boundaries of 3-5 $\mathrm{nm}$ in width. Within the grain boundaries, the lattice image reveals a distinct spot arrangement compared to that in the adjacent grains, indicating that a different structure or phase exists at the grain boundaries. 

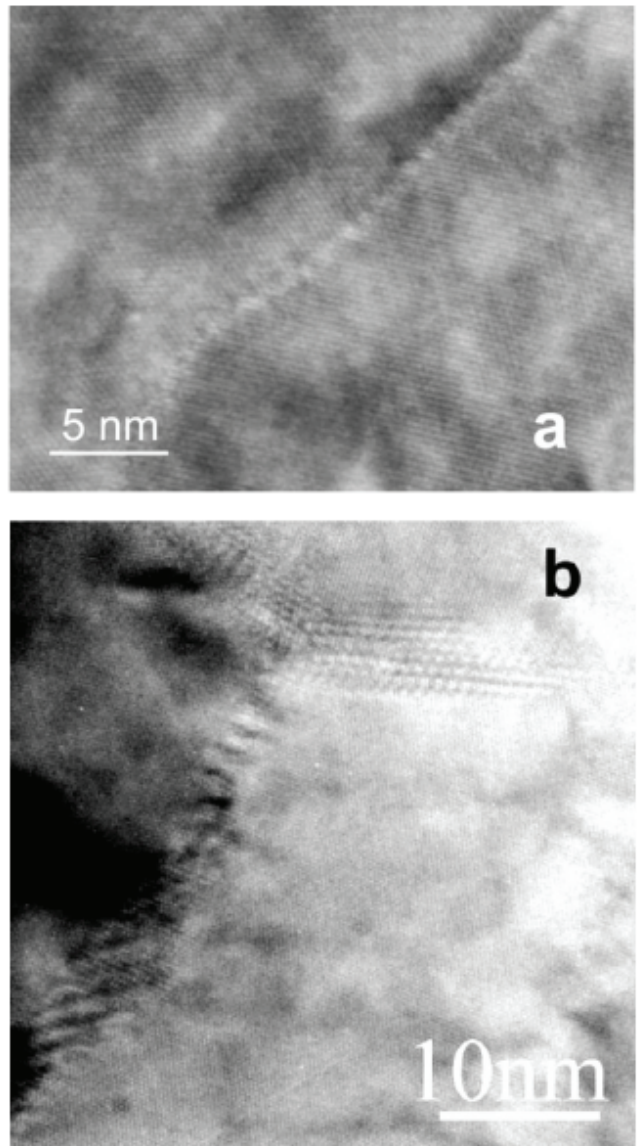

Figure 3. High-resolution electron microscopy images of $\mathrm{Zn}_{1-x} \mathrm{Mn}_{x} \mathrm{O}$ thin films: (a) $x=$ 0.01 ; (b) $x=0.05$.

Changes in the film structure and phase composition are also revealed by comparing the electron diffraction patterns of the films. Figure 4 shows the polycrystalline electron diffraction patterns of $\mathrm{Zn}_{1-x} \mathrm{Mn}_{x} \mathrm{O}$ thin films. Figure 4(a) compares the films with $x=$ 0.01 (left) and $x=0.03$ (right). Compared with the left pattern, more diffraction rings are observed in the right pattern. All the diffraction rings on the left side from the film with $x$ $=0.01$ are indexed consistently with the [001] zone axis of the hexagonal wurtzite $\mathrm{ZnO}$ structure, and all the additional diffraction rings appearing in the right pattern from the film doped with $x=0.03$ are indexed with wurtzite $\mathrm{ZnO}$ structure with random orientation. No evidence was found that manganese oxides or other secondary phases exist in the $\mathrm{Zn}_{1-x} \mathrm{Mn}_{x} \mathrm{O}$ thin films for $x$ below 0.03 . However, as the Mn concentration reaches $5 \%$, as shown in figure 4(b), an extra diffraction ring located within the (100) ring of $\mathrm{ZnO}$ was observed. Since (100) is the innermost diffraction ring for $\mathrm{ZnO}$ hexagonal structure, this extra diffraction ring is not from hexagonal $\mathrm{ZnO}$, but must be from a secondary phase. Comparing the experimental pattern and simulated results, we conclude that the extra diffraction ring is $\mathrm{Mn}_{2} \mathrm{O}_{3}$ (211). Although both the x-ray diffraction and electron diffraction results indicate deterioration of the (001) orientation of $\mathrm{ZnO}$ thin films with $\mathrm{Mn}$ doping, the existence of a $\mathrm{Mn}_{2} \mathrm{O}_{3}$ secondary phase in 5\% Mn-doped $\mathrm{ZnO}$ is only revealed by electron diffraction, suggesting that electron diffraction is more powerful than $\mathrm{x}$-ray dif- 

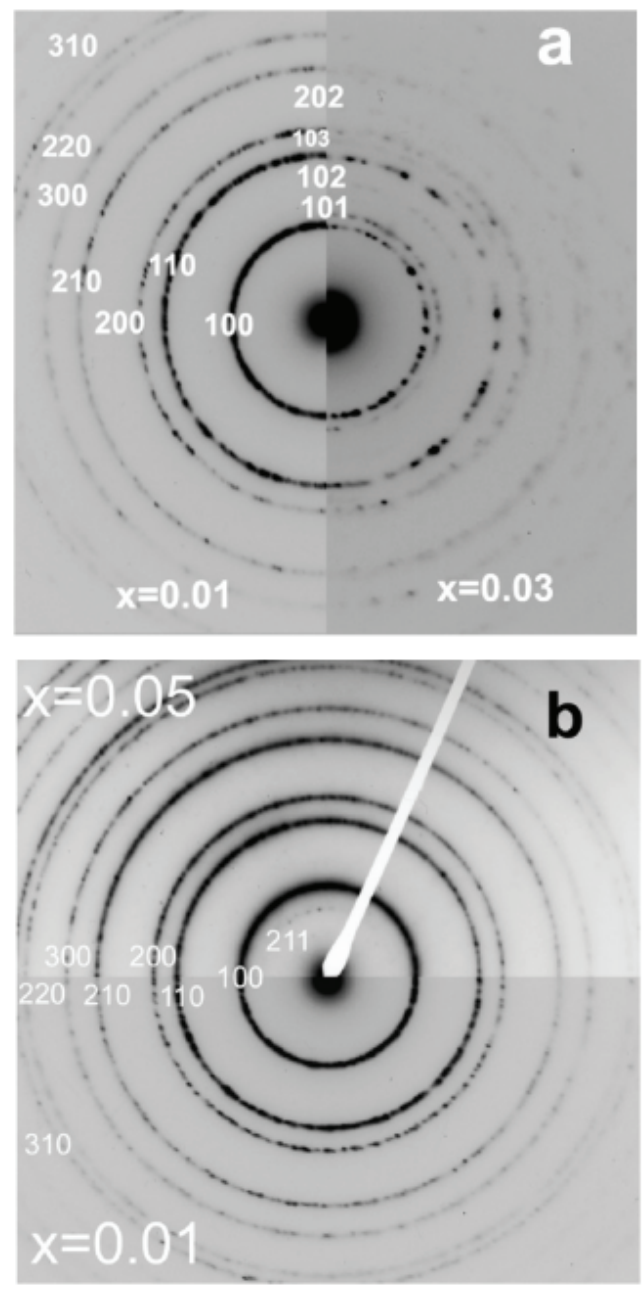

Figure 4. Electron diffraction patterns of $\mathrm{Zn}_{1-x} \mathrm{Mn}_{x} \mathrm{O}$ thin films. (a) Comparison of $x=$ 0.01 (left) and $x=0.03$ (right). For $x=0.01$, the diffraction rings are indexed to be (100) to (310) from the centre to the outside; for $x=0.03$, only the extra diffraction rings that do not appear at the left-hand side are indexed. (b) Comparison of $x=0.01$ (bottom) and $x=$ 0.05 (top). For $x=0.05$, the innermost diffraction ring is indexed as $\mathrm{Mn}_{2} \mathrm{O}_{3}(211)$.

fraction in studying the structure of slightly doped $\mathrm{ZnO}$ thin films. The appearance of the $\mathrm{Mn}_{2} \mathrm{O}_{3}$ secondary phase in the $5 \% \mathrm{Mn}$-doped $\mathrm{ZnO}$ thin film is consistent with the HREM result shown in figure 3 , and it is reasonable to believe that $\mathrm{Mn}_{2} \mathrm{O}_{3}$ phase aggregates at the grain boundaries.

Magnetization of the $\mathrm{Zn}_{1-x} \mathrm{Mn}_{x} \mathrm{O}$ thin films was measured at room temperature as a function of the applied magnetic field, as shown in figure 5. The films measured are 200 $\mathrm{nm}$ thick. The magnetic field was applied parallel to the film surface, and the diamagnetic contribution from the Si substrate was subtracted. Shown in the bottom inset of figure 5 are the magnetization curves at the low-field range. The magnetization curves show hysteresis, with remanences and the coercivities very similar to those reported for $\mathrm{ZnO}$ thin films [12] and nanorods [13] implanted with Mn, suggesting the existence of ferromag- 


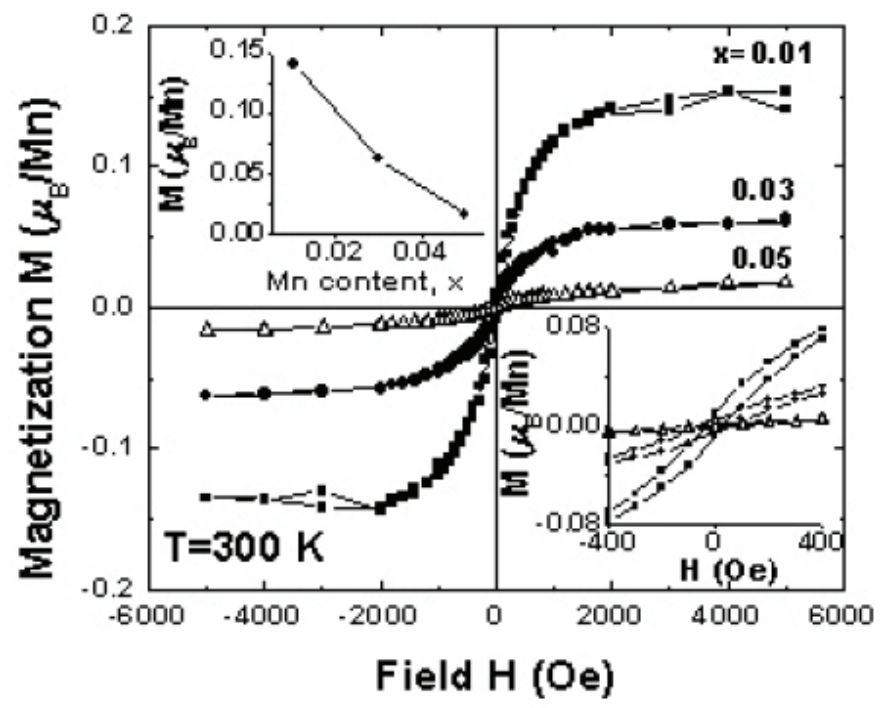

Figure 5. Field dependence of magnetization curves of $\mathrm{Zn}_{1-x} \mathrm{Mn}_{x} \mathrm{O}$ thin films $(x=0.01$, 0.03 , and 0.05$)$ at $300 \mathrm{~K}$. Top inset: Mn concentration dependence of the saturation magnetic moment of $\mathrm{Zn}_{1-x} \mathrm{Mn}_{x} \mathrm{O}$ thin films at $300 \mathrm{~K}$. Bottom inset: enlarged part of the magnetization curves at a low field range.

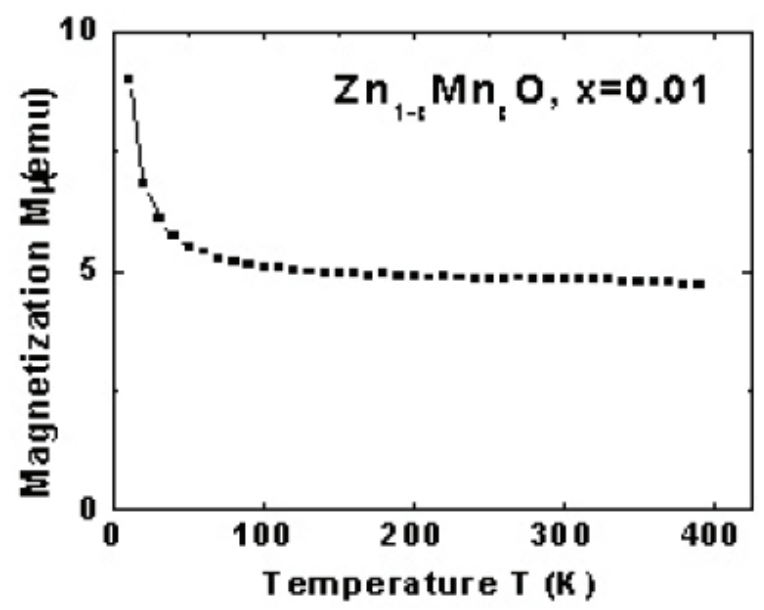

Figure 6. Temperature dependence of magnetization curve of a $\mathrm{Zn}_{1-x} \mathrm{Mn}_{x} \mathrm{O}(x=0.01)$ thin film measured at 500 Oe.

netic ordering at room temperature. The top inset of figure 5 shows the Mn concentration dependence of the magnetic moment at 5000 Oe. The moment gradually decreases as the Mn concentration increases. The highest moment observed is about $0.15 \mu_{\mathrm{B}} / \mathrm{Mn}$ in the film doped with $1 \% \mathrm{Mn}$.

Figure 6 shows the temperature dependence of magnetization measured at $500 \mathrm{Oe}$ for a $\mathrm{Zn}_{1-x} \mathrm{Mn}_{x} \mathrm{O}$ thin film with $x=0.01$. At low temperatures the curve exhibits paramagnetic behavior, with magnetization decreasing quickly as temperature increases. Above $100 \mathrm{~K}$, the magnetization becomes much less sensitive to temperature, and is sustained up to the highest temperature measured $(400 \mathrm{~K})$. This temperature dependence of magne- 
tization suggests that there is coexistence of a paramagnetic component that is prominent at low temperatures and a ferromagnetic component with a $T_{\mathrm{C}}$ higher than $400 \mathrm{~K}$. By taking into account a combination of a paramagnetic component and a ferromagnetic component, and fitting the paramagnetic component with

$$
\chi=\frac{M}{H}=\frac{N \mu_{\mathrm{eff}}^{2}}{3 k_{\mathrm{B}} T},
$$

the effective magnetic moment is calculated to be $\mu_{\text {eff }}=4.75 \mu_{\mathrm{B}} / \mathrm{Mn}$. Assuming that $\mathrm{Mn}$ exists as $\mathrm{Mn}^{2+}$ and considering that the maximum spin-only moment of $\mathrm{Mn}^{2+}$ is $5.92 \mu_{\mathrm{B}}$ $\mathrm{Mn}^{2+}$, it is estimated that about $64 \% \mathrm{Mn}^{2+}$ are in a paramagnetic state, for example, being isolated from each other. The low magnetic moment as shown in figure 5 also suggests that only a small fraction of $\mathrm{Mn}^{2+}$ participates in the ferromagnetic ordering.

It has been shown that in bulk $\mathrm{Zn}-\mathrm{Mn}-\mathrm{O}$ materials sintered at a low temperature of $500{ }^{\circ} \mathrm{C}$, manganese oxides exist with as little as only $1 \% \mathrm{Mn}$ doping [8]. But the results reported here show that $\mathrm{Zn}_{1-x} \mathrm{Mn}_{x} \mathrm{O}$ thin films without secondary phases can be prepared at the same temperature by pulsed laser deposition, which is a non-equilibrium process and may favor the incorporation of $\mathrm{Mn}$ into $\mathrm{ZnO}$ [11]. Our results also suggest that roomtemperature ferromagnetism can be realized in $\mathrm{Zn}_{1-x} \mathrm{Mn}_{x} \mathrm{O}$ thin films without involving magnetic impurity phases. The mechanism for intrinsic ferromagnetism in $\mathrm{Zn}_{1-x} \mathrm{Mn}_{x} \mathrm{O}$ still remains unclear. Carrier-mediated ferromagnetism was initially proposed, and it is believed that $\mathrm{p}$-type conductivity favor $\mathrm{s}$ this mechanism $[1,2]$. An alternative mechanism is the "F-center" model, in which the oxygen vacancy plays an important role [14, 15]. In summary, we have systemically studied the structure and magnetic properties of $\mathrm{Zn}_{1-x} \mathrm{Mn}_{x} \mathrm{O}$ thin films grown by pulsed laser deposition. Mn doping results in variations in the lattice parameter $c$ and deterioration of the (001) orientation of the films. No manganese oxides or other secondary phases are observed in the films with Mn concentrations below 0.03 , but the $\mathrm{Mn}_{2} \mathrm{O}_{3}$ phase appears as the $\mathrm{Mn}$ concentration reaches 0.05 . Ferromagnetism is observed at room temperature in the $\mathrm{Zn}_{1-x} \mathrm{Mn}_{x} \mathrm{O}$ thin films and does not appear to be related to manganese oxides or other impurity phases, at least for Mn concentrations below 0.03 .

\section{Acknowledgments}

This research is supported by the U.S. National Science Foundation Materials Research Science and Engineering Center (NSF-MRSEC), the W. M. Keck Foundation, Nebraska Research Initiative and Nebraska Center for Materials and Nanoscience.

\section{References}

[1] Dietl T, Ohno H, Matsukura F, Cibert J, and Ferrand D 2000 Science 2871019

[2] Sato K and Katayama-Yoshida H 2000 Japan. J. Appl. Phys. 239 L555

[3] Pearton S J, Heo W H, Ivill M, Norton D P, and Steiner T 2004 Semicond. Sci. Technol. 19 R59

[4] Fukumura T, Jin Z, Kawasaki M, Shono T, Hasegawa T, Koshihara S, and Koinuma H 2001 Appl. Phys. Lett. 78958

[5] Tiwari A, Jin C, Kvit A, Kumar D, Muth J F, and Narayan J 2002 Solid State Commun. 121 371

[6] Jung S W, An S J, Yi G, Jung C U, Lee S, and Cho S 2002 Appl. Phys. Lett. 804561 
[7] Sharma P, Gupta A, Rao K V, Owens F J, Sharma R, Ahuja R, Guillen J M O, Johansson B, and Gehring G A 2003 Nat. Mater. 2673

[8] Zhang J, Skomski R, and Sellmyer D J 2005 J. Appl. Phys. 9710 D303

[9] Kundaliya D, Ogale S, Lofland S, Dhar S, Metting C, Shinde S, Ma Z, Varughese B, Ramanujachary K, Salamanca-Riba L, and Venkatesan T 2004 Nat. Mater. 3709

[10] García M A, Ruiz-González M L, Quesada A, Costa-Krämer J L, Fernández J F, Khatib S J, Wennberg A, Caballero A C, Martín-González M S, Villegas M, Briones F, González-Calbet J M, and Hernando A 2005 Phys. Rev. Lett. 94217206

[11] Fukumura T, Jin Z, Ohtomo A, Koinuma H, and Kawasaki M 1999 Appl. Phys. Lett. 753366

[12] Heo Y W, Ivill M P, Ip K, Norton D P, Pearton S J, Kelly J G, Rairigh R, Hebard A F, and Steiner T 2004 Appl. Phys. Lett. 842292

[13] Ip K, Frazier M, Heo Y W, Norton D P, Abernathy C R, Pearton S J, Kelly J, Rairigh R, Hebard A F, Zavada J M, and Wilson R G 2003 J. Vac. Sci. Technol. B 211476

[14] Venkatesan M, Fitzgerald C B, Lunney J G, and Coey J M D 2004 Phys. Rev. Lett. 93177206

[15] Coey J M D, Venkatesan M, and Fitzgerald C B 2005 Nat. Mater. 4173 